\title{
APLICAÇÃO DAS FERRAMENTAS LEAN MANUFACTURING E PREVISÃO DE DEMANDA EM UM RESTAURANTE UNIVERSITÁRIO: UM ESTUDO DE CASO
}

\author{
Fernando de Araújo (UFG) faraujo@ufg.br \\ Aline Andrade Lima (UFU) aline7356@gmail.com \\ Daniel Lucas Pereira de Assis Pacheco (UFU) danielpassis@gmail.com \\ Henrique Altivo de Andrade (UFU) henriqueh9@ @otmail.com \\ Izabela Nahás (UFU) izabelanahas@ufu.br
}

\section{Resumo}

O presente trabalho tem como objetivo apresentar a filosofia Lean Manufacturing, abordando principalmente os oito desperdícios, em especial o desperdício superprodução, e relacioná-lo com área de Planejamento e Controle da Produção (PCP), mais especificamente com previsão de demanda, por meio da aplicação de um estudo de caso aplicado em um restaurante universitário. Atualmente é perceptível grandes mudanças no cenário econômico de organizações em buscas de melhorias nas áreas econômica e financeira. Dessa forma, diversas organizações têm procurado novas ferramentas e métodos para obter o melhor desempenho dentro do ramo em que atuam. Portanto o referido trabalho tem como proposta evidenciar aplicações de ferramentas que auxiliam nas decisões estratégicas e operacionais.

Palavras-Chaves: Lean Manufacturing; Previsão de Demanda; Produção Enxuta; Restaurante Universitário.

\section{Introdução}

A filosofia Lean Manufacturing, conhecida também por manufatura enxuta, é um método que teve origem no Japão e que possui como principal objetivo minimizar os desperdícios na produção sem que haja necessidade de sacrificar a produtividade (OHNO, 1997).

Monden (1998) afirma que o nivelamento de produção da Toyota, empresa na qual surgiu a primeira variante da manufatura enxuta, era baseado na ideia de fabricar para previsão, ou seja, por meio de um plano de previsão mensal determinava-se a quantidade total a ser produzida diariamente pelo sistema de produção.

O processo de previsão de demanda, conforme proposto por Lustosa et al (2008), inicia-se com a definição dos objetivos a serem alcançados com a sua implantação e da abrangência do processo. Em seguida, coletam-se dados pertinentes à previsão, os quais determinarão a 
natureza do método a ser eventualmente utilizado. Este é então selecionado e após uma série de testes para avaliar sua confiabilidade, é efetuada sua implantação.

O Restaurante Universitário da Universidade Federal de Uberlândia (UFU) - Campus Pontal, doravante denominado RU, é responsável pelo fornecimento de refeições aos alunos do referido campus. Devido à natureza dos alimentos, a previsão de demanda é de grande importância, dada sua perecividade. A escolha de quanto produzir é baseada apenas na experiência do tomador de decisão, sem nenhum auxílio mais robusto.

Portanto o objetivo do presente trabalho é propor um método de previsão de demanda, ou seja, do número esperado de alunos e servidores a serem servidos no horário de almoço, de forma a auxiliar na tomada de decisão pelo gestor, a partir da análise de métodos consolidados no assunto e posteriormente na análise de erros.

\section{Revisão Bibliográfica}

\subsection{Manufatura Enxuta}

O Sistema Toyota de Produção (STP) foi criado por Eiji Toyoda após a Segunda Guerra Mundial. O cenário pós-guerra culminou, para o Japão, em crise econômica e concorrência do mercado internacional (LIKER, 2005).

O STP é um sistema alternativo a produção em massa. Tem como objetivo eliminar desperdícios e otimizar os recursos usados na produção (WOMACK et al., 2006).

Ao abordar a manufatura enxuta, alguns termos básicos são mencionados: perdas por superprodução, just-in-time (JIT) e separação homem-máquina.

Há dois tipos de superprodução: quantitativa (a produção é maior do que a necessária e o restante é levado para o estoque) e antecipada (o bem é produzido antes de ser necessário) (SHINGO, 1989).

O conceito de JIT é entendido como produzir os itens que são necessários na quantidade e nos momentos corretos. A qualidade e a flexibilidade são os principais objetivos operacionais, visando a melhoria contínua e a eliminação de desperdícios. Para alcançar esses objetivos o JIT atua na redução de estoque. A implantação depende de três fatores: fluxo contínuo, produção puxada e takt-time (CORRÊA; et al, 2012). 
A separação homem-máquina, automação ou jidoka é entendida como a máquina dotada de inteligência humana. Constitui de sistemas instalados em linhas de produção e em máquina que possibilita esta ou o operador interromper o processo de produção caso haja detecção de falhas durante o processo. Este conceito está relacionado com a autonomia da máquina. Dessa forma, é possível que um trabalhador opere mais de um posto de trabalho, aumentando a produtividade. Possui como objetivos evitar a propagação de falhas e aumentar a eficiência do trabalhador (LIKER, 2005).

Seguindo o pensamento de tornar o desempenho de uma organização mais satisfatório tanto para os colaboradores, quanto para o consumidor final, eliminando os desperdícios, há a prática dos cinco princípios da gestão Lean que devem ser aplicados seguindo o passo a passo, segundo Bertani (2012), que são:

- Identificar valor: valor é definido apenas pelo consumidor final, e é apenas significativo quando é expresso em termos de um produto específico que atende as necessidades do consumidor a um preço e tempo específicos;

- Identificar o fluxo de valor: conjunto de todas as ações específicas que agregam valor ao produto;

- Fluxo contínuo: produto é trabalhado de forma contínua;

- Produção puxada: método de controle de produção no qual as atividades posteriores sinalizam suas necessidades para atividades anteriores;

- Perfeição: busca pela melhoria contínua de todos os processos, sempre almejando a perfeição, algo sempre passível de melhorias.

\subsubsection{Os oito desperdícios do Lean Manufacturing}

Segundo Ohno (1997), a produção enxuta possui como objetivo eliminar os desperdícios nos processos de produção. Por definição, desperdício é qualquer ação ou etapa que não agregue valor em um processo.

Originalmente foram encontrados, por Taiichi Ohno (1997) - engenheiro chefe da Toyota, sete desperdícios. O oitavo foi identificado por Liker (2005). São estes:

- Processamento impróprio: compreende o processamento além do que o cliente pede, ou seja, não há o cumprimento de uma sequência lógica de como funciona o processo; 
- Superprodução: produção em excesso, isto é, a saída de materiais é maior do que a necessária;

- Estoque: armazenamento em excesso de matéria-prima e produtos finalizados ou não.

- Transporte: é ligado ao transporte desnecessário de materiais, funcionários e informações durante qualquer processo;

- Movimentação: movimento desnecessário de equipamentos ou funcionários que participam do processo;

- Retrabalho: é a necessidade de refazer algo devido a algum erro ou defeito existente no processo;

- Espera: máquinas, funcionários e outros recursos que estão parados durante o processo;

Conhecimento pessoal: desperdício de conhecimento intelectual e habilidades de colaboradores que não são aproveitadas (LIKER, 2005).

Segundo Ohno (1997), o pior desperdício é superprodução pois este gera desperdícios de recursos materiais e humanos.

\subsubsection{Ferramentas da Produção Enxuta}

De acordo com Bertani (2012) a filosofia Lean se apoia em ferramentas que buscam sempre a otimização do espaço de trabalho, o tornando sempre mais eficiente e rápido. Abaixo é listado algumas delas:

$-5 S$

$-\mathrm{A} 3$

- Andon;

- Cadeia de ajuda;

- Evento Kaizen (EK);

- Fluxo contínuo;

- Gestão visual;

- Layout celular;

- Mapa de fluxo de valor (MFV);

- Nivelamento de produção ou Heijunka;

- Nivelamento de trabalho; 
- Poka-Yoke;

- Sistemas puxados;

- SMED ou troca rápida de ferramentas;

- Trabalho padronizado.

\subsection{Planejamento e Controle da Produção}

Com a revolução industrial surge a produção de bens de consumo, elabora-se meios de produzir e desenvolve o sistema de produção em massa. A partir dessa inovação desenvolveuse ferramentas para realizar medição e análise produtiva. Henry Gantt criou um sistema de programação de produção fundamentado em cálculos e gráficos levando em consideração duas restrições: capacidade e o tempo do processo. O gráfico é conhecido até os dias atuais como "gráfico de Gantt" (LUTOSA; et al, 2008).

A gestão de informações é a base para realizar o planejamento e controle da produção, quase todos os departamentos de uma organização são geradores de informações ocasionando assim um alto volume das mesmas (SLACK; et al, 2009).

A partir dessas informações é possível tomar algumas decisões, tais como: quando e quanto deve ser produzido, quando será necessário produzir e quem estará executando as atividades. A técnica de cálculos para responder essas questões é denominada de Material Requirements Planning - MRP (SLACK; et al, 2009).

Pode-se utilizar a previsão de demanda como base para elaborar um MRP que consiste em um método cujo tem como objetivo determinar a quantidade necessária de materiais para disparar a linha de produção, desta forma auxilia os gestores na tomada de decisão (SLACK; et al, 2009).

\subsection{Previsão de Demanda}

Existem três categorias para a classificação das técnicas de previsão: qualitativas, análise de séries temporais e modelos causais. As técnicas de caráter qualitativo são utilizadas quando não existe um banco de dados e sua análise é realizada a partir de opiniões e estimativas. As técnicas fundamentadas em análises de séries temporais consistem na utilização de dados passados para prever os dados futuros. As análises que tem como princípio os modelos causais se constituem de uma relação da demanda com algum fator no meio ambiente que 
possuem ocorrência de causa e efeito (DAVIS; et al, 2001). O presente trabalho abordará análises de séries temporais.

Pode-se aplicar a previsão de demanda no médio, curto e/ou longo prazo. De acordo com o espaço de tempo existe um método recomendado (CORRÊA; et al, 2012).

Previsão de demanda no curto prazo que contempla um período de até quatro meses, baseia-se na hipótese de que o cenário futuro permanecerá com as mesmas tendências do cenário passado, essa técnica consiste na aplicação de projeções. Para a elaboração da projeção faz- se uso de dados históricos que são submetidos a modelos matemáticos na busca a identificar o comportamento destes dados (CORRÊA; et al, 2012).

De acordo com a tendência dos dados é possível escolher uma hipótese de comportamento. Para a previsão de curto prazo, podem ser utilizadas quatro hipóteses: permanência que os dados apresentam comportamento estável ou uniforme, sem acrescimento e decréscimo e também não expõe sazonalidade passível de identificação. Sazonal com permanência a identificação de sazonalidade, porém não existe acréscimo e decréscimo. Trajetória com decréscimo ou acréscimo de acordo com uma taxa uniforme. Sazonal com trajetória se identifica a sazonalidade com um acréscimo ou decréscimo a uma taxa uniforme (CORREAA; et al, 2012). Após a escolha da hipótese subsequentemente deve-se escolher o modelo (CORRÊA; et al, 2012).

\subsubsection{Modelos para previsão de demanda no curto prazo}

Um dos modelos utilizados para realizar a previsão de demanda no curto prazo é a média móvel. A média móvel é utilizada quando se adere a hipótese de permanência, nesse cenário a variação da demanda ocorre em sua maioria de forma aleatória e sua distribuição possui simetria com a média. Sendo assim aplica-se a equação 1 com o objetivo de suavizar essa variação (CORRÊA; et al, 2012):

$$
P_{t}=\frac{D_{t-1}+D_{t-2}+\cdots+D_{t-n}}{n}
$$

onde ${ }^{D}$ representa a demanda, ${ }^{t}$ é o período de tempo e ${ }^{n}$ é a quantidade de períodos. Quanto maior o n maior a suavização das variações. 
Tubino (2009) também propõe a utilização da média móvel centrada e um índice de sazonalidade para casos em que certa sazonalidade seja detectada. A média móvel centrada é calculada conforme equação 2 :

$$
M M C_{t}=\frac{D_{t}+D_{t-1}+D_{t-2}+\cdots+D_{t-n}+D_{t-n+1}}{n}
$$

onde ${ }^{D}$ representa a demanda, ${ }^{t}$ é o período de tempo e ${ }^{n}$ é a quantidade de períodos.

Já o índice de sazonalidade é calculado conforme equação 3:

$$
I S_{t}=\frac{D_{t}}{M M C_{t}}
$$

onde ${ }^{D}$ representa a demanda, ${ }^{t}$ é o período de tempo e $M M C_{t}$ é a média móvel centrada.

Para obter-se então a demanda prevista basta reaplicar o índice de sazonalidade médio sobre a demanda média da conforme equação 4 (TUBINO, 2009):

$$
\text { Demanda prevista }=\text { demanda média }+ \text { demanda média } *(I S-1)
$$

Utiliza-se o Erro Médio Percentual Absoluto (MAPE), conforme equação 5 para determinação do método adequado. O que apresentar menor MAPE deve ser selecionado.

$$
\text { MAPE }=\sum_{i=1}^{n} \frac{\left|\frac{X_{i}-\hat{X}_{i}}{X_{i}}\right| * 100}{n}
$$

onde $X_{i}$ é a demanda real, $\widehat{X}_{\bar{i}}$ é a demanda prevista e n é a quantidade de períodos.

\section{Metodologia}

O presente trabalho teve início com a realização de pesquisas bibliográficas em livros e artigos específicos sobre planejamento e controle da produção e manufatura enxuta. Após conhecer os princípios de redução de desperdícios da ferramenta Lean aprofundou-se os estudos na previsão de demanda que é uma ferramenta do PCP que pode ser aplicado na redução de desperdícios. 
O estudo de caso presente no artigo foi desenvolvido no RU do campus Pontal da UFU e realizou-se algumas entrevistas de caráter exploratório no período de março a junho de 2019, com a gestora da empresa terceirizada, que é responsável pelo fornecimento e distribuição das refeições dentro do restaurante. Na primeira entrevista identificou-se a dificuldade para elaborar a previsão de demanda com uma boa precisão. Frente a esse cenário houve a obtenção dos dados históricos para serem analisados através da gestora devido ao restaurante possuir um software para controle dos dados. Após fazer uma análise aprofundada dos dados, ocorreu a submissão desses em métodos conhecidos de previsão de demanda. Para análise gráfica, cálculos e aplicação dos métodos foi utilizado planilhas de cálculos presente no software Excel.

\section{Estudo de caso}

Conforme explicitado no objetivo do presente trabalho, este propõe um método de previsão de demanda para o RU da UFU - Campus Pontal a fim de determinar quantas pessoas devem ser esperadas a cada dia. Devido a facilidade de sua futura implementação por parte dos responsáveis pelo RU, decidimos aplicar a média móvel e a média centrada com sazonalidade, e por meio do MAPE determinar qual delas é mais apropriada para a situação do RU. Para os nossos cálculos, utilizamos 8 ciclos semanais levando em conta 5 dias de funcionamento no horário de almoço como nossos dados históricos. Os valores da demanda real para tais ciclos se encontram na Tabela 1.

Tabela 1 - Demanda real

\begin{tabular}{|c|c|c|c|c|c|c|c|c|}
\hline \multirow{2}{*}{ Dia } & \multicolumn{8}{|c|}{ Semana } \\
\hline & Ciclo 1 & Ciclo 2 & Ciclo 3 & Ciclo 4 & Ciclo 5 & Ciclo 6 & Ciclo 7 & Ciclo 8 \\
\hline Segunda & 477 & 558 & 612 & 477 & 565 & 475 & 489 & 413 \\
\hline Terça & 601 & 620 & 619 & 663 & 638 & 602 & 594 & 578 \\
\hline Quarta & 589 & 666 & 738 & 566 & 650 & 596 & 533 & 557 \\
\hline Quinta & 729 & 655 & 595 & 612 & 596 & 715 & 598 & 638 \\
\hline Sexta & 436 & 556 & 564 & 416 & 403 & 453 & 477 & 545 \\
\hline Total & 2.832 & 3.055 & 3.128 & 2.734 & 2.852 & 2.841 & 2.691 & 2731 \\
\hline
\end{tabular}


O gráfico correspondente aos 8 ciclos (semanas) e sua demanda real está ilustrado na Figura 1.

Figura 1 - Gráfico da demanda real

\section{Demanda real 8 ciclos}

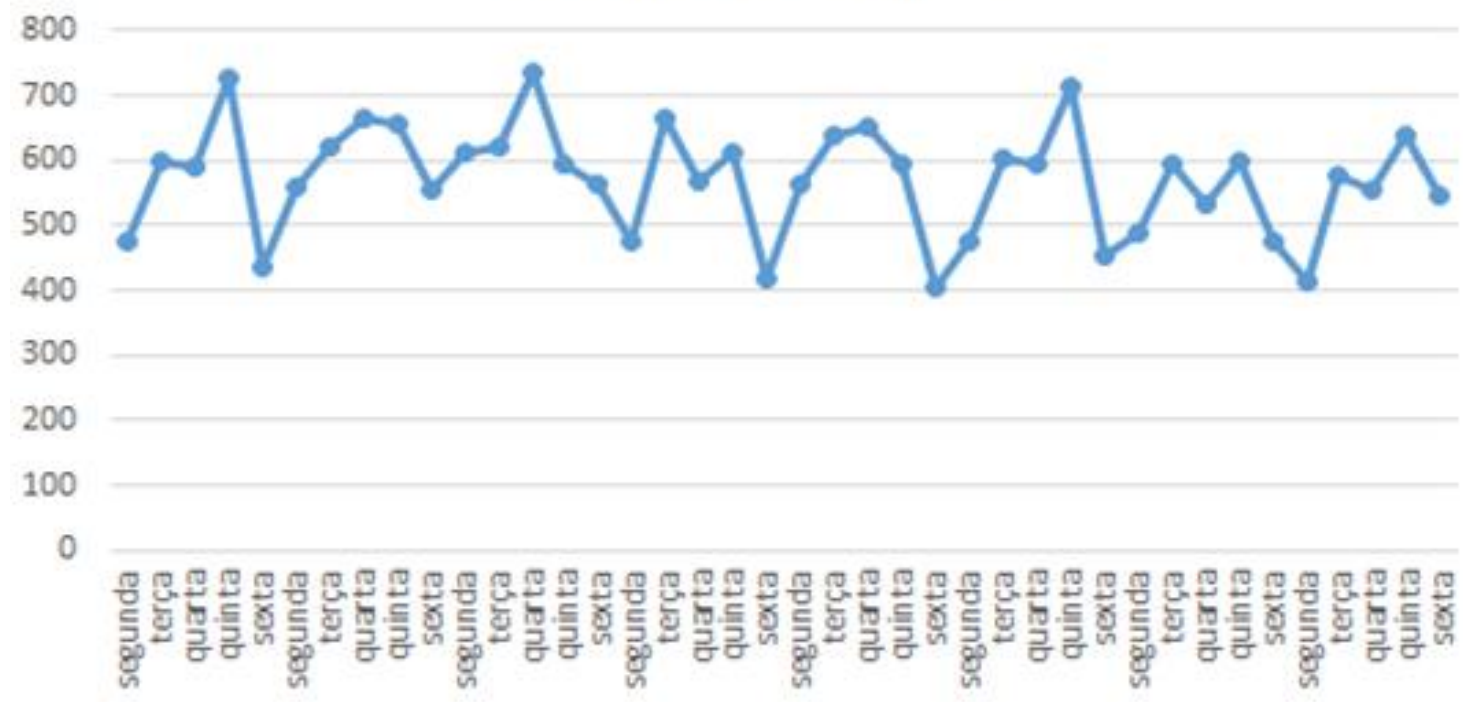

Fonte: Autoria própria (2019)

Efetuando a previsão de demanda para o $9^{\circ}$ ciclo utilizando a média móvel (equação 1) com 5 ciclos, obtivemos os seguintes valores e gráfico, conforme constam na Tabela 2 e Figura 2. Também foi calculado o MAPE do método a partir da equação, o qual corresponde a $9,2435 \%$.

Tabela 2 - Previsão de demanda utilizando média móvel com 5 ciclos

\begin{tabular}{ccc}
\hline Dia & Demanda real & MM5 \\
\hline Segunda & 544 & 553,96 \\
Terça & 553 & 556,64 \\
Quarta & 635 & 552,24 \\
Quinta & 485 & 555 \\
Sexta & 473 & 549,92 \\
\hline
\end{tabular}


Figura 2 - Gráfico média móvel com 5 ciclos

\section{Média Móvel com 5 ciclos}

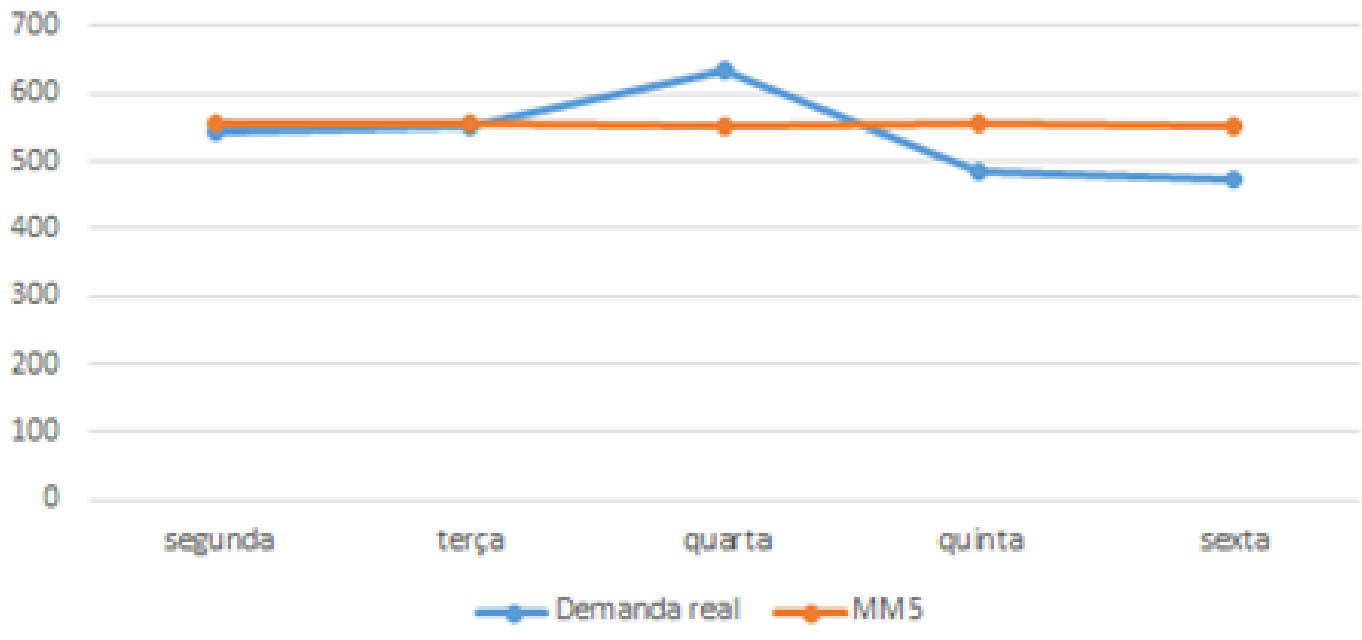

Fonte: Autoria própria (2019)

Em seguida, efetuou-se a média móvel com 8 ciclos, o equivalente a 2 meses. Os resultados constam conforme Tabela 3 e Figura 3. O valor do MAPE corresponde a 11,3479\%.

Tabela 3 - Previsão de demanda utilizando média móvel com 8 ciclos

\begin{tabular}{ccc}
\hline Dia & Demanda real & MM8 \\
\hline Segunda & 544 & 571,6 \\
Terça & 553 & 573,275 \\
Quarta & 635 & 572,075 \\
Quinta & 485 & 573,225 \\
Sexta & 473 & 567,125 \\
\hline
\end{tabular}


Figura 3 - Gráfico média móvel com 8 ciclos

\section{Média Móvel com 8 ciclos}

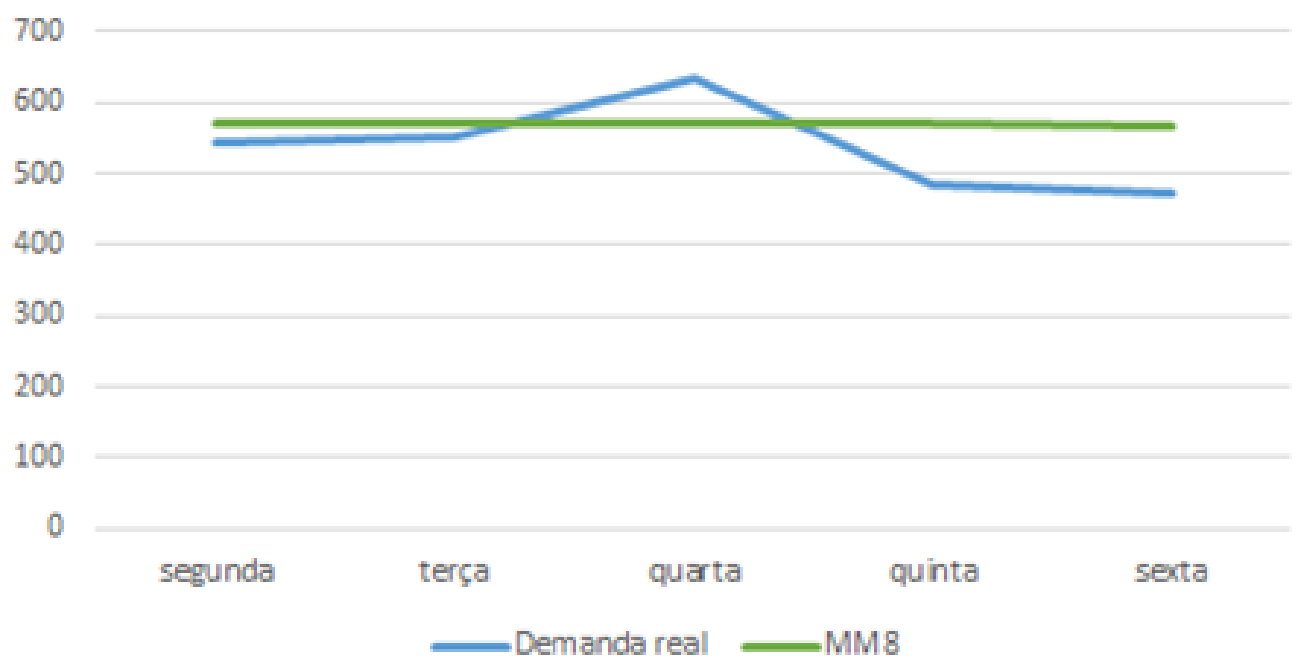

Fonte: Autoria própria (2019)

A previsão de demanda envolvendo uma média móvel centrada com índice de sazonalidade também foi efetuada (equações 2 e 3). Os índices de sazonalidade médios para cada dia da semana estão discriminados conforme constam na Tabela 4.

Tabela 4 - Índices de sazonalidade

IS médio

\begin{tabular}{lc}
\hline Segunda & 0,893836 \\
Terça & 1,084172 \\
Quarta & 1,067911 \\
Quinta & 1,122504 \\
Sexta & 0,823229 \\
\hline
\end{tabular}

Fonte: Autoria própria (2019)

Assim sendo, a previsão de demanda através da média centrada e o índice de sazonalidade está ilustrada na Tabela 5 e Figura 4. O MAPE corresponde a 10,9628\%. 
Tabela 5 - Previsão de demanda através da média centrada e índice de sazonalidade

\begin{tabular}{ccc}
\hline Dia & Demanda real & MMC \\
\hline Segunda & 544 & 511,0557 \\
Terça & 553 & 619,8815 \\
Quarta & 635 & 610,584 \\
Quinta & 485 & 641,7976 \\
Sexta & 473 & 470,6856 \\
\hline
\end{tabular}

Fonte: Autoria própria (2019)

Figura 4 - Gráfico média móvel centrada

\section{Média Móvel Centrada}

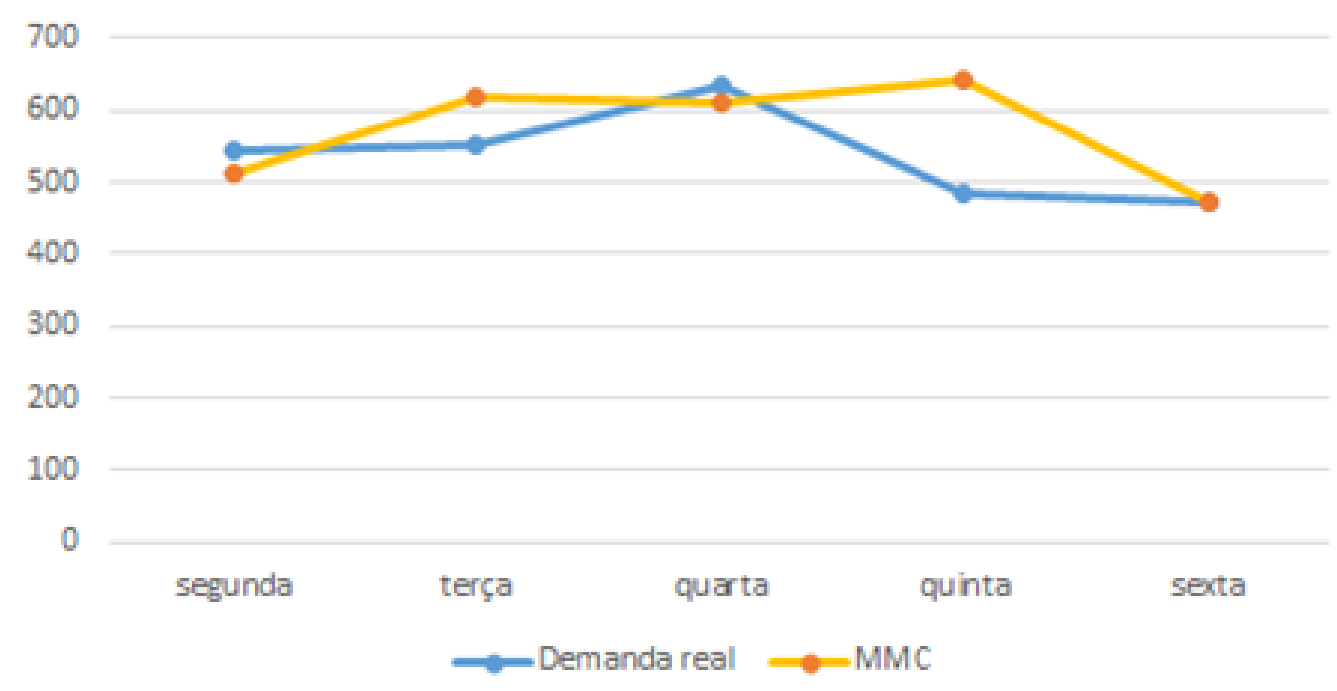

Fonte: Autoria própria (2019)

Os MAPEs foram tabelados conforme ilustrado na Tabela 6.

Tabela 6 - MAPEs

\begin{tabular}{cc}
\hline Método & MAPE \\
\hline MM5 & $9,2435 \%$ \\
MM8 & $11,3479 \%$ \\
MMC & 10,9628 \\
\hline
\end{tabular}




\section{Conclusão}

A iteração entre a UFU e o RU tornou possível a aplicação dos métodos de previsão de demanda e do erro médio (\%), buscando reduzir o desperdício de superprodução a partir da realização da previsão de demanda de forma adequada. Após a aplicação do método da média móvel para os ciclos 5 e 8 encontrou-se a previsão de demanda para 9 ciclos e foi calculado o erro, o erro para 5 ciclos é menor quando comparado com o erro para 8 ciclos.

Posteriormente foi utilizado a média móvel centrada para obtenção da previsão e também foi calculado o erro. Ao relacionar os erros médios percentuais houve a identificação da média móvel para 5 ciclos como sendo a mais adequada para ser empregada na obtenção do número de pessoas que frequentam o RU. Com a realização desse estudo de caso foi possível obter a previsão para o nono ciclo, que pode ser replicada para outros períodos.

Contudo, o menor erro para o método que envolve menos informações (média móvel simples com 5 ciclos) pode ser explicado de diversas maneiras, inclusive pela não representatividade do ciclo 9 em relação ao quadro geral. Semanas atípicas são comuns no ano letivo, como também feriados e atividades extracurriculares refletem no consumo no restaurante universitário. Para eventuais trabalhos posteriores propõe-se a análise de outras variáveis que o presente trabalho não leva em consideração, para que haja uma adequação maior da demanda real em relação com a demanda prevista e em consequência a diminuição de erros.

\section{REFERÊNCIAS}

BERTANI, Thiago Moreno. Lean Healthcare: Recomendações para Implantações dos Conceitos de Produção Enxuta em Ambientes Hospitalares. 2012. Dissertação (Mestrado em Processos e Gestão de Operações) - Escola de Engenharia de São Carlos, Universidade de São Paulo, São Carlos, 2012. DOI: 10.11606/D.18.2012.tde-29102012-235205. Disponível em: 〈http://www.teses.usp.br/teses/disponiveis/ 18/18156/tde-29102012-235205/fr.php>. Acesso em: 29 out. 2019.

CORRÊA, Henrique L.; et al. Planejamento e Controle da Produção: MRPII/ERP: Conceitos, Uso e Implantação: Base para SAP, Oracle Applications e Outros Softwares Integrados de Gestão. 5.ed. São

Paulo: Atlas, 2012.

DAVIS, Mark M.; et al. Fundamentos da Administração da Produção. 3. ed. Porto Alegre: Bookman, 2001.

LIKER, J.K. O Modelo Toyota: 14 Princípios de Gestão do maior Fabricante do Mundo. Porto Alegre: Bookman, 2005. 
LUSTOSA, Leonardo.; et al. Planejamento e Controle da Produção. Rio de Janeiro: Elsevier, 2008.

MONDEN, Y. Toyota Production System: An Integrated Approach to Just-In-Time. 3ed. Norcross: Engineering \& Management Press, 1998.

OHNO, T. O Sistema Toyota de Produção: Além da Produção em Larga Escala. Porto Alegre: Bookman, 1997.

SHINGO, Shigeo. O Sistema Toyota de Produção do ponto de vista da Engenharia de Produção. $2^{\text {a }}$ Ed. Bookman, Porto Alegre, 1996.

SLACK, Nigel; et al. Administração da Produção. 3. ed. São Paulo: Atlas, 2009.

TUBINO, D. F. Planejamento e Controle da Produção: Teoria e Prática. Atlas, 2009.

WOMACK, J. P. et al. A Máquina que mudou o Mundo. 8. ed. Rio de Janeiro: Elsevier, 2004. 